\title{
A METAPHYSIAL ABNORMALITY
}

\section{Report of a Case with Features of Metaphysial Dysostosis}

\author{
Peter Kilburn, Ilkley, England
}

Metaphysial dysostosis is a disease with important genetic implications and is characterised by selectively disturbed endochondral bone formation; involvement of the extremities results in reduced stature.

Patients showing the classical criteria of metaphysial dysostosis as described originally by Jansen in 1934 appear to be excessively rare, although Cameron, Young and Sissons (1954) reported a case which resembled closely the original description. Nevertheless, many authors have described cases having some of the features of the condition in its more completely developed form. The patient described by Jansen showed severe involvement of the metaphyses of all the long bones including the tubular bones of the hands and feet; the epiphyses showed a remarkable freedom from any change.

In 1949 Schmid described a modified form of the condition, with less marked metaphysial changes, but with a reduction of stature and a disturbance of gait. In the Schmid type of metaphysial dysostosis the larger long bones are involved, with only infrequent changes in the smaller tubular bones of the hands and feet. It appears to be a characteristic of this variant that the subjects are normal at birth, and later develop a waddling gait, bowing of legs and a short stature. There is often a strong hereditary history, although the frequency of sporadic cases suggests a high mutation rate.

Catel (1961) recognised that there may be a combination of metaphysial and epiphysial changes in some of these cases. Kozlowski and Zychowicz (1962) reported the case of a girl, which appeared to be transitional between the full-fledged Jansen form of the condition and the Schmid type, in which there were abnormalities of the fingers, with metaphysial irregularities, but the bones were long and slender with narrow epiphysial plates. In 1966 Kozlowski and Budzinska reported two cases with metaphysial and epiphysial changes; one of these patients was a boy aged eight years and the other was a girl of twelve years.

McKusick (1964) reported the association of metaphysial dysostosis with thin hair in the Amish as a recessive inherited feature. These cases showed changes in the tibial metaphyses, the radial metaphyses, and also in the metaphyses of the metacarpal bones and phalanges. The phalanges, metacarpal bones and finger nails were short; occasionally coeliac disease was present.

In a report of twenty-one cases of the Schmid variant, Miller and Paul (1964) commented on the severe bowing of the lower limbs, with decrease of stature. The condition manifested itself most severely between the ages of two to five years, after which there was a tendency to improve. They noted that the joints adjacent to the affected metaphyses were enlarged but not tender. Radiographs showed widening of the epiphysial lines, with irregular metaphyses and islands of uncalcified cartilage extending into the metaphyses. Evans and Caffey (1958) reported a non-familial case in which the ribs were involved: biopsy showed disordered columns of cartilage with irregular zones of provisional calcification.

Schmidt, Beçak, Beçak, Soibelman, Queiroz, Lorga, Secaf, Antonio and Carvalho (1963) reported a boy aged twelve years with pronounced genu valgum, in whom the upper limbs showed metaphysial deformity with alteration of texture as well as the contour of the bones, but with no changes in the hands. Discussing the natural history of the condition, Rosenbloom and Smith (1965) reviewed twenty-four cases and two sporadic ones, and demonstrated a wide variance in severity of involvement.

vol. 55 B, No. 3, AUgUST 1973 
Bonne and Sybrandy (1964) demonstrated that there may be symmetrical involvement of all the long bones as well as of the tubular bones of the hands, feet and vertebral bodies.

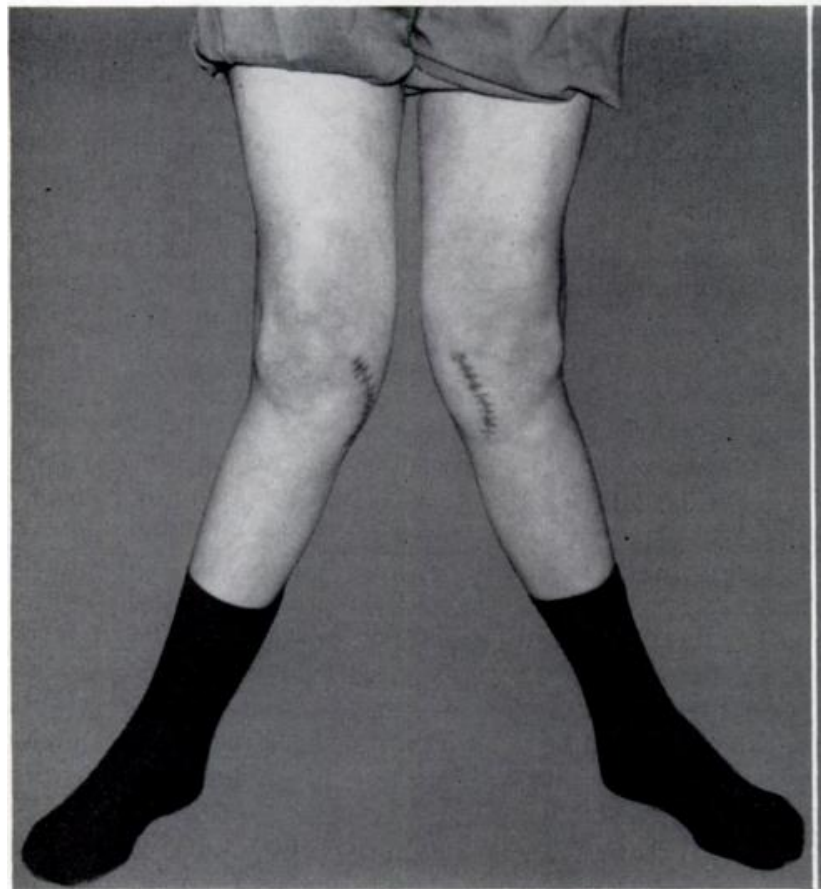

FIG. 1

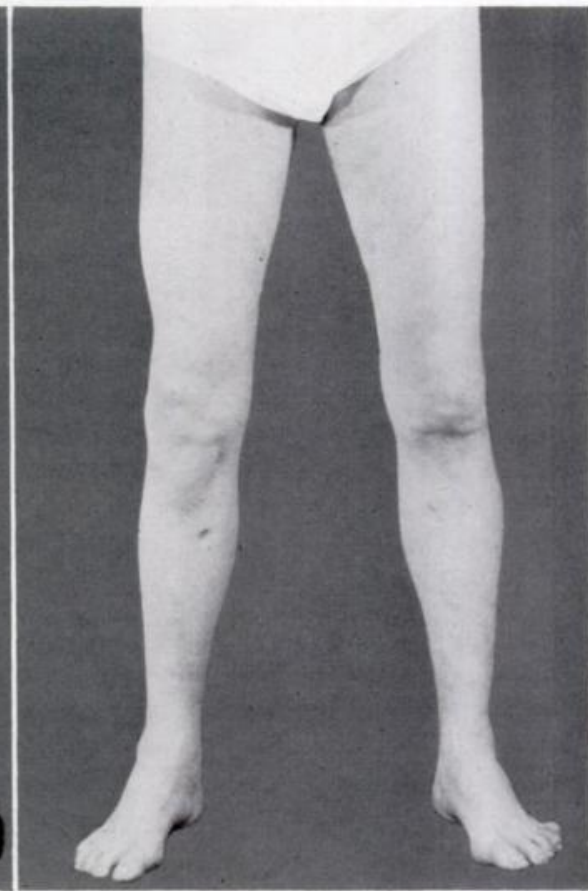

FIG. 2

Photographs showing the severe genu valgum before operation and its correction by upper tibial osteotomies.

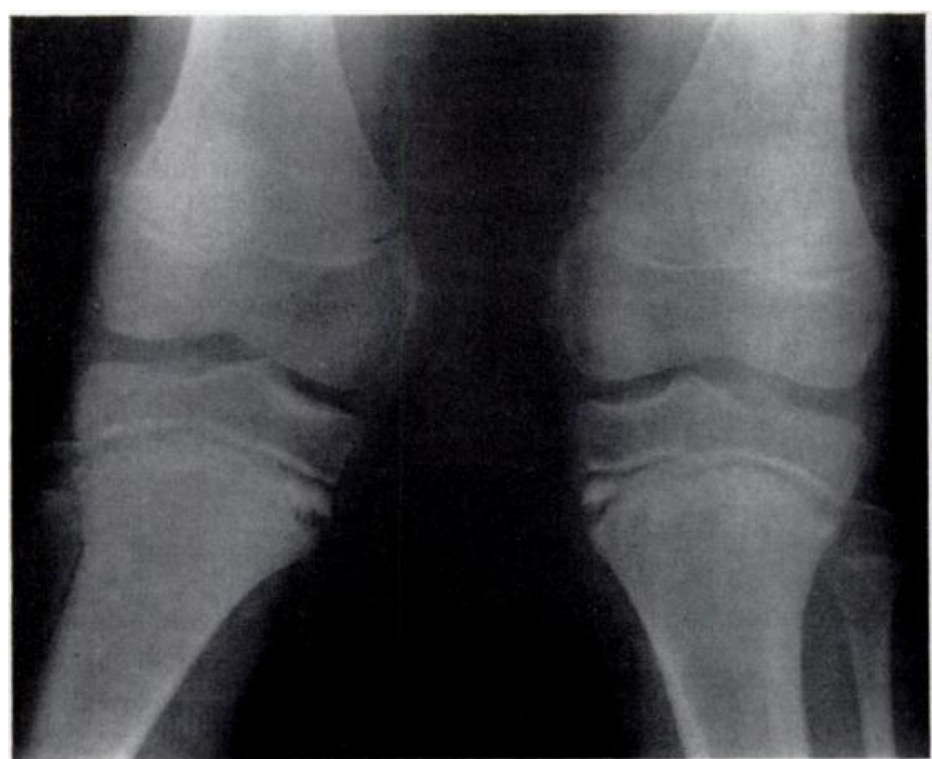

FiG. 3

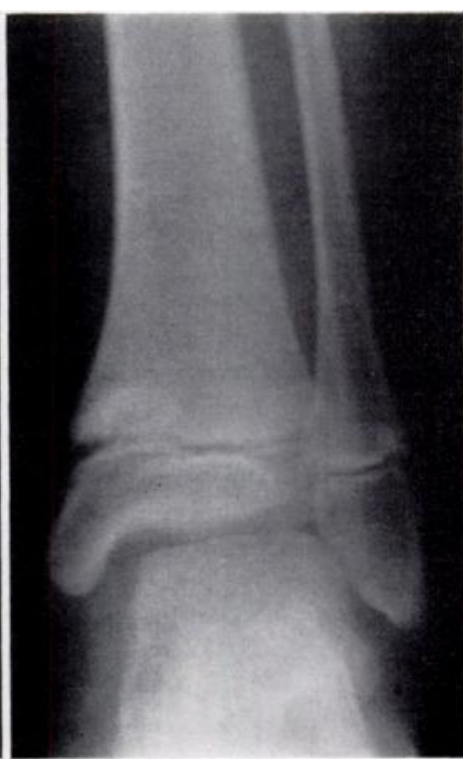

FIG. 4

Figure 3-Radiograph showing partial disruption of the medial halves of both tibial metaphyses. Figure 4-Lower tibial metaphysis showing early changes.

It is of interest that in all the accounts that have been published no significant alteration of blood chemistry has been recorded. 


\section{CASE REPORT}

A boy aged twelve years was first seen because of severe knock-knees, which had been present for a year (Figs. 1 and 2). The boy's stature was normal for his age, and examination of the skull, thoracic cage and upper limbs failed to reveal any abnormality. Urine and blood examinations were normal. The blood urea was 28 milligrams/100 millilitres. Serum calcium and serum phosphorus were within normal limits. The serum alkaline phosphatase was $16 \mathrm{King}$ Armstrong units. The Wassermann reaction was negative.

The parents and siblings showed no skeletal abnormality; the grandparents were not seen but were alleged to have been normal; this seemed to be confirmed by photographs.

Radiographs of both knees showed some disruption of the medial halves of the upper tibial metaphyses (Fig. 3). There Yar: nnologous changes in the medial part of the lower tibial epiphysis on the left side (Fig. 4) and possibly early changes in the metaphysis of the lower humeral epiphysis on the lateral aspect (Fig. 5).

Biopsy specimens were taken from the upper tibial metaphysis adjacent to the epiphysis. The material consisted of cartilage. Sections (Fig. 6) were submitted to Dr Henry L. Jaffe who reported that the tissue removed from the lesion of the epiphysial-diaphysial junction on the medial side of the left tibia was composed essentially of cartilage. He saw no possibility that the cartilage in question represented portions of the epiphysial cartilage plate. Taking the histological appearance

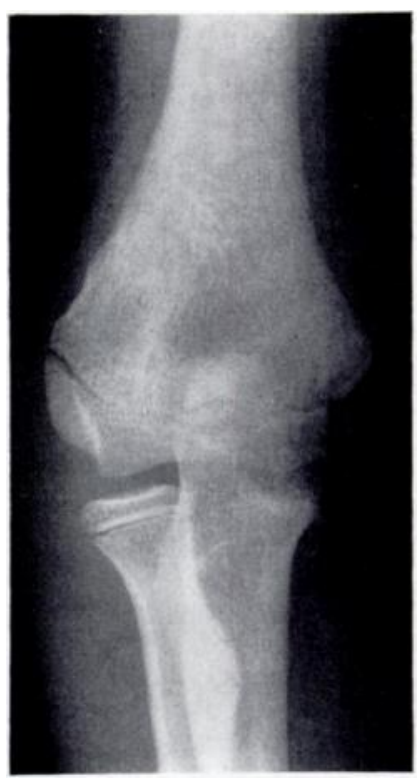

FIG. 5

Possible early changes in the lateral humeral metaphysis. in conjunction with the radiographs, he thought that if small punctate radiopacities, such as were seen at the knee, were found throughout the width of the junctional areas in many other metaphyses, a diagnosis of metaphysial dysostosis was probable.

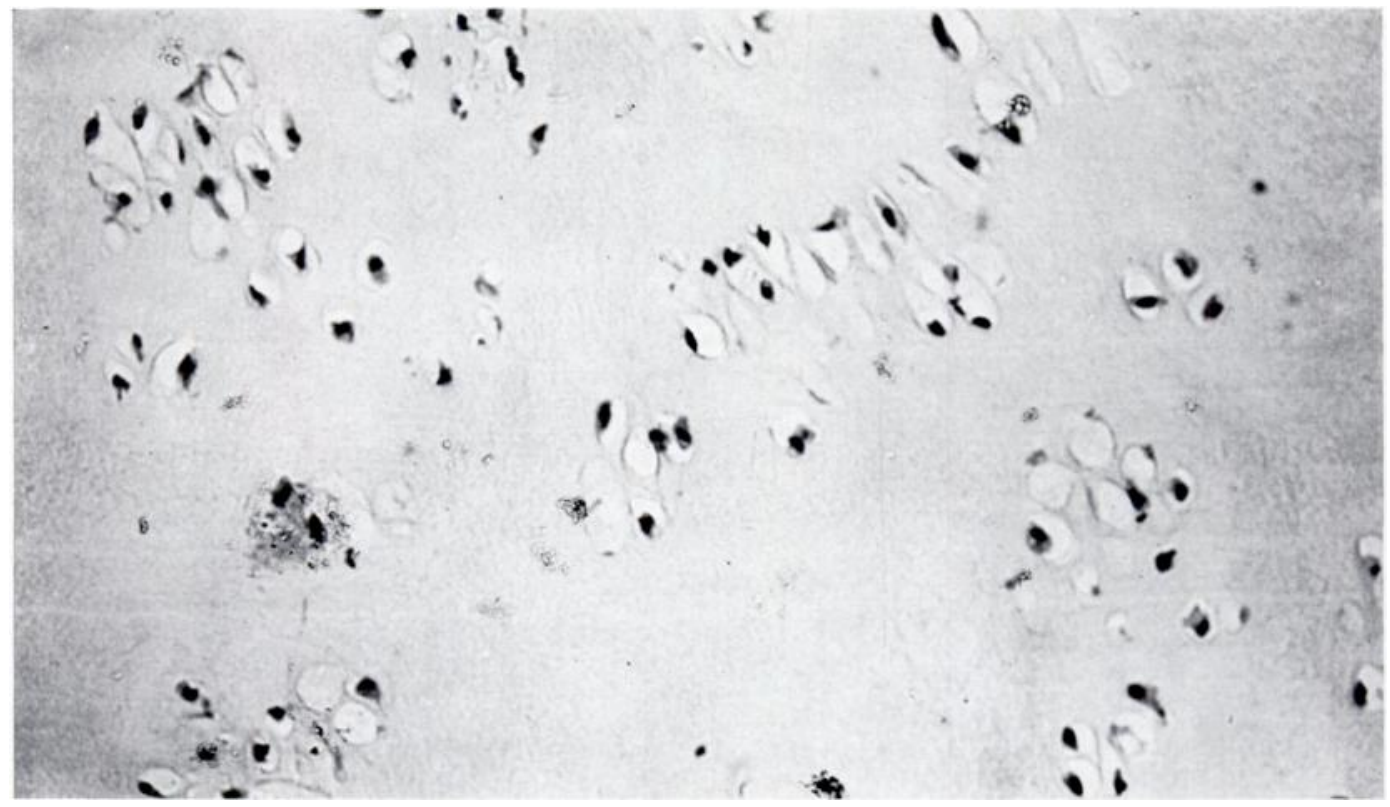

FIG. 6

Section of cartilage removed from upper tibial metaphysis. $(\times 250$.

VOL. 55 B, NO. 3, AUGUSt 1973 
His impression was that the condition represented a rather localised developmental anomaly, and not a real tumour.

Treatment-Initially, epiphysial stapling was tried, but this completely failed to improve the severe genu valgum. Bilateral tibial osteotomies were therefore done, with full correction of the deformity (Fig. 2).

\section{DISCUSSION}

Cases of metaphysial dysostosis as originally described by Jansen (1934) are excessively rare. Many cases are recorded in the literature showing some of the features of the classical picture, known as the Schmid syndrome. Most of the less pronounced cases show shortness of stature and bowing of the legs. The case described here appears to fit loosely into the Schmid category, although such features as the late onset, the normal stature and severe genu valgum are noteworthy.

\section{SUMMARY}

1. A case is reported of a twelve-year-old boy showing normal stature and severe genu valgum.

2. The radiological and histological features suggested metaphysial dysostosis, possibly of the Schmid type.

It gives me much pleasure to thank Dr Henry L. Jaffe and Professor Robert Roaf for many helpful suggestions.

\section{REFERENCES}

Bonne, A. J., and Sybrandy, S. (1964): Report Netherlands Orthopaedic Society. Journal of Bone and Joint Surgery, 46-B, 573.

Cameron, J. A. P., Young, W. B., and Sissons, H. A. (1954): Metaphysial Dysostosis. Journal of Bone and Joint Surgery, 36-B, 622.

CATEL, W. (1961): Differentialdiagnose von Krankheitssymptome bei Kindern und Jugendlichen. Band 1, p. 96. Stuttgart: Georg Thieme Verlag.

Evans, R., and CAFFEY, J. (1958): Metaphyseal Dysostosis Resembling Vitamin-D Refractory Rickets. American Journal of Diseases of Children, 95, 640.

JANSEN, M. (1934): Über atypische Chondrodystrophie (Achondroplasie) und über eine noch nicht beschriebene angeborene Wachstumsstörung des Knochensystems: Metaphysäre Dysostosis. Zeitschrift für orthopädische Chirurgie, 61, 253.

Kozlowskı, K., and Budzinska, A. (1966): Combined Metaphyseal and Epiphyseal Dysostosis. American Journal of Roentgenology, Radium Therapy and Nuclear Medicine, 97, 21.

Kozlowskı, K., and Zychowicz, C. (1962): Metaphyseal Dysostosis of Mixed Type in a Female Child. American Journal of Roentgenology, Radium Therapy and Nuclear Medicine, 88, 443.

McKusick, V. A. (1964): Metaphyseal Dysostosis and Thin Hair: A "New" Recessively Inherited Syndrome? Lancet, $1,832$.

Miller, S. M., and Paul, L. W. (1964): Roentgen Observations in Familial Metaphyseal Dysostosis. Radiology, 83, 665.

Rosenbloom, A. L., and Smith, D. W. (1965): The Natural History of Metaphyseal Dysostosis. Journal of Paediatrics, 66, 857.

ScнміD, F. (1949): Beitrag zur Dysostosis enchondralis metaphysaria. Monatsschrift für Kinderheilkunde, 97, 393.

Schmidt, B. J., Beçak, W., Beçak, M. L., Solbelman, I., Queiroz, A. da S., lorga, A. P., Secaf, F., Antonio, C. F., and Carvalho, A. de A. (1963): Metaphyseal Dysostosis. Journal of Paediatrics, 63, 106. 